\title{
Privatización y reestructuración de la industria de equipos ferroviarios en México (1993-2012): el caso de Concarril-Bombardier
}

\author{
Privatization and restructuring of the railway equipment industry in \\ Mexico (1993-2012): the study case of Concarril-Bombardier
}

\section{Resumen}

Este trabajo se compone de dos partes. En la primera se analizan algunos aspectos del proceso de privatización de la industria de equipos ferroviarios que han sido soslayados por la política y el discurso neoliberal. A contracorriente de la concepción dominante, que señala al deterioro financiero, la ineficiencia productiva y la baja competitividad en el mercado como las causas principales de la privatización de empresas públicas en México, en este artículo, el autor muestra que la compra de la industria paraestatal de equipos ferroviarios por parte del capital privado extranjero estuvo fuertemente motivada por los alcances en el desarrollo tecnológico de las empresas públicas y por su posición estratégica en el mercado. La privatización, en este caso, no fue simplemente el rescate de una industria en crisis, en realidad significó la transferencia al capital privado de activos públicos rentables y del control de segmentos del mercado altamente lucrativos. En la segunda parte del artículo se analizael proceso de reestructuración de esta industria bajo las pautas marcadas por la entrada de empresas trasnacionales. Se observa que después de un periodo de desindustrialización parcial, actualmente la organización de la producción y el trabajo en esta industria descansa sobre mecanismos que permiten a la gran empresa trasladar con relativa facilidad los costos de las crisis sobre la clase trabajadora y el conjunto local de proveedores y subcontratistas altamente especializados, quienes sobreviven a la sombra de una desindustrialización latente basadaen la capacidad de rápida reconfiguración de funciones y relocalización de activos que hoy en día tienen las empresas extranjeras de esta industria.

\section{Abstract}

Adrián Escamilla Trejo* :
This work consists of two parts. At first, some aspects of privatization of railway equipment industry that have been overlooked by discourseand neoliberal politics are analyzed. Against the dominant conception, that pointing to the financial deterioration, productive inefficiency and low competitiveness in the market as the main causes of the privatization of public enterprises in Mexico, in this article, the author finds that the purchase of the stateowned railway equipment industry by foreign private capital was strongly motivated by the achievements in technological development of public enterprises and its strategic position in the market. Privatization, in this case, it was not just the rescue of an industry in crisis, actually meant the transfer to private capitalof the profitable public assets and the control of the highly lucrative market segments. In the second part of this article the restructuring of this industry under the guidelines set by the entry of multinational companies are analyzed. It is observed that after a period of partial deindustrialization, currently the organization of production and work in this industry rests on mechanisms that allow large companies to transfer with relative ease the costs of the crisis on the working class and the set of suppliers and highly specialized local subcontractors, who survive in the shadow of a latent industrialization based on the ability of reconfiguration of functions and relocation of assets that today have foreign enterprises in this industry.

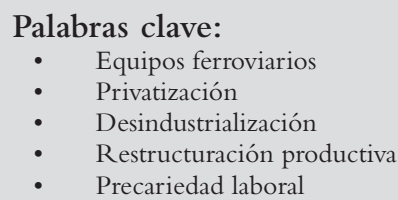

JEL: L92, L98, O14
Keywords:

- Railway Equipment

- Privatization

- Deindustrialization

Productive Restructuring

Job Insecurity

* Doctor en Economía. Profesor del Área de Historia Económica de la Facultad de Economía, unam. adrianopovich@hotmail.com

El presente trabajo es un primer resultado de una línea de investigación alterna que surgió mientras realizaba los estudios de doctorado en historia económica. Agradezco a mi comité tutorial: Dra. Esperanza Fujigaki, Dr. Carlos Tello y Dra. Isabel Rueda Peiró, por sus críticas y observaciones a los borradores de 


\section{Introducción}

En 1952 el gobierno federal, a través de Nacional Financiera (Nafinsa), fundó la empresa Constructora Nacional de Carros de Ferrocarril S. A. (CNCF o Concarril), única fabricante de equipo de transporte ferroviario en México hasta la década de 1990. Esta empresa fue instalada al sur del estado de Hidalgo, en el corazón de la Altiplanicie Pulquera, junto a otras dos empresas que a partir de 1960 fueron de participación estatal mayoritaria: Diésel Nacional S. A. (1952) y Fábrica Nacional de Maquinaria Textil “Toyoda de México” S. A. (1954), después convertida en Siderúrgica Nacional S. A. (1960). Las tres plantas conformaron el núcleo del Complejo Industrial Sahagún, una entidad que constituyó el primer intento en el país por crear un polo de desarrollo industrial basado en la fabricación de bienes de capital, y que durante las décadas de 1960 y 1970 se convirtió en el eje de la industria paraestatal de equipos de transporte. ${ }^{1}$

Concarril se creó con el doble objetivo de satisfacer la demanda de transporte de un mercado interno en expansión y contribuir a la rehabilitación del equipo ferroviario del país bajo mejores condiciones financieras. En su momento, la Oficina de Investigaciones Industriales del Banco de México (OII), observó que el alquiler y la compra de equipos en su mayoría de segunda mano fabricados en Estados Unidos, que realizaban las diversas compañías de transporte ferroviario de manera creciente a partir de 1945, reforzaba las perturbaciones macroeconómicas del periodo (el ciclo inflación-devaluación característico del crecimiento económico de México hasta 1954). Evitar la salida de divisas se convirtió así en una de las principales razones para promover la instalación de una empresa de este tipo en México. Por su parte, la saturación de la capacidad instalada de los fabricantes estadounidenses de equipos ferroviarios durante la posguerra contribuyó a despejar algunas dudas que tenían los promotores de este proyecto. ${ }^{2}$

1 Hasta antes de 1952 en México había una escasa producción de equipo ferroviario rodante de carga y transporte que se efectuaba principalmente dentro de los talleres de las distintas compañías ferroviarias del país. Algunas de estas compañías habían conformado en ciertos puntos del país importantes complejos de producción ferroviaria que contaban con una base técnica y laboral especializada (como los de Ferrocarriles Nacionales de México, ubicados en Aguascalientes); sin embargo, sus actividades se concentraban en la rehabilitación del equipo importado, sobre todo de Estados Unidos, incluido el equipo de tracción (locomotoras). La reparación en general, la producción de refacciones y la reconstrucción de equipo en desuso fueron las actividades más notables de esta incipiente industria. Para un análisis de esta historia véanse los distintos trabajos de Guillermo Guajardo Soto [i.e. Guajardo (2010), "La industria de equipos ferroviarios en México"].

2 Para un análisis sobre la creación de ésta y otras empresas que conformaron uno de los ejes más importantes de la participación del Estado en la industria de bienes de capital, véase mi tesis de doctorado: Escamilla (2015), El Complejo Industrial Sahagún (1952-1995). 


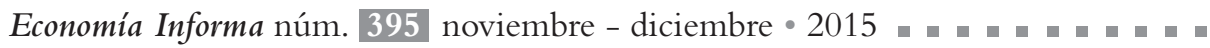

Después de experimentar un proceso complicado de asimilación tecnológica, integración productiva nacional y adiestramiento de cuadros técnicos y mano de obra, hacia 1970 Concarril se había convertido en una empresa rentable (generadora de utilidades netas año con año), cuya composición nacional de la producción alcanzaba, en promedio, aproximadamente 78\% de su valor total anual. El grado de diversificación productiva alcanzado era sobresaliente; se contaba con capacidad instalada para fabricar desde simples tolvas y plataformas hasta complejos cabuses, coches express y carros tanque. $\mathrm{Su}$ eficacia productiva quedó demostrada con el triunfo obtenido en varias licitaciones internacionales, Concarril exportaba con frecuencia diversos equipos a Estados Unidos y en algunas ocasiones vendió productos a ciertos países de Latinoamérica. El desarrollo de múltiples competencias tecnológicas le permitió a esta empresa iniciar el aprendizaje para la fabricación de los trenes del Sistema de Transporte Colectivo (STC) "Metro" de la Ciudad de México en 1974, bajo la asesoría de la firma francesa Alsthom (fabricante original de los primeros "metros" que circularon en México); lo que en su momento constituyó un hito en la historia de la industrialización del país. ${ }^{3}$

Sin embargo, a pesar de los esfuerzos que se hicieron desde su fundación para asimilar y dominar el cambio tecnológico y de los éxitos obtenidos (en cuanto al desarrollo incipiente de tecnología propia y de nuevos productos), la estructura productiva de CNCF presentaba varios problemas y limitaciones que se hicieron patentes con la crisis financiera que estalló en esta empresa entre 1974-1976. ${ }^{4}$ Básicamente, las razones de esta crisis, que por su importancia merecen estudiarse en otro momento, obedecen a una peculiar política de precios y ventas, impuesta por la Secretaría de Hacienda desde el nacimiento mismo de la empresa, que impedía a Concarril vender en condiciones de mercado su producción a otras entidades públicas (como Ferrocarriles Nacionales de México y, más adelante, al propio STC), y que la forzaban, al mismo tiempo, a financiar a estos clientes bajo términos que con el tiempo se volvieron totalmente desfavorables para ella. ${ }^{5}$

3 Escamilla (2015), El Complejo Industrial Sahagún... capítulos II-IV.

4 En realidad, de las tres empresas principales que conformaban el Complejo Industrial Sahagún (CIS) en la década de 1970, Concarril fue la que menos pérdidas financieras presentó (entre 15-19\% del total de las pérdidas del CIS anuales para el periodo 1975-1980).

5 Mientras la empresa Concarril pudo financiar a sus clientes imponiéndoles tasas de interés en promedio iguales o incluso ligeramente superiores a las que, por su parte, ella misma contrataba para obtener financiamiento interno y externo (principalmente a través de Nafinsa), este peculiar mecanismo de venta no ocasionó daños relevantes sobre la estructura financiera de la empresa. Pero cuando en la década de 1970 Nafinsa elevó el costo de su financiamiento a las entidades públicas por motivo de las dificultades del periodo para obtener créditos externos, Concarril se vio en una situación financiera comprometida. Entonces, las tasas de interés cobradas por el financiamiento que 
La situación al interior de la empresa agudizaba el problema financiero los costos laborales y administrativos crecientes derivados de una organización productiva relativamente rígida, un alto grado de obsolescencia funcional de la maquinaria instalada y dificultades para la producción de otro tipo de bienes de capital no ferroviarios que permitieran elevar el grado de ocupación de la capacidad instalada, fueron algunos de los factores que impidieron frenar la tendencia al crecimiento de los costos reales de la producción por encima de sus precios de venta, aspecto que fue característico de esta y otras empresas públicas del sector industrial. ${ }^{6}$

A partir de esta coyuntura de la crisis financiera de los años setenta, se inició un proceso de reconversión industrial dirigido por el propio gobierno, basado en los principios de racionalidad, cambio tecnológico y reorganización de las líneas productivas que dio como resultado una restructuración administrativa de las empresas públicas en México a partir del período 19761978. En el caso de Concarril hay un aspecto que destaca: se emprendió una importante modernización tecnológica, expresada tanto en la inversión en maquinaria de punta como en la actualización de los criterios organizativos y el desarrollo de nuevos productos competitivos en el mercado mundial (que implicaron la llegada de nuevos socios tecnológicos).?

El resultado de este proceso de reconversión -que sin duda se conoce más por sus efectos traumáticos sobre la sociedad, debido a los drásticos ajustes que suscitó en la plantilla de trabajadores contratados-, fue la continuación en un nivel más avanzado del tan ansiado desarrollo de tecnología propia. Aspecto, cabe decir desde ahora que la retórica de las privatizaciones que predominó en las décadas de 1980 y 1990 ignoró o encubrió, y que por muchos años permaneció sin atención, debajo de la escandalosa problemática financiera del sector paraestatal de la economía que fue finalmente el argumento que en público se sostuvo para justificar su desincorporación y, en el caso de CNCF, su venta al capital privado.

otorgaba a sus grandes clientes resultaron ser en promedio inferiores a las tasas de interés pagadas por ella misma por la contratación de capital externo. Así, el costo financiero de la producción se incrementó notablemente. Y lo hizo aún más después de las devaluaciones de 1976 y las sucesivas ocurridas en la década de 1980, que incrementaron sus pérdidas en cambios, ya que buena parte de la deuda contraída por esta empresa estaba fijada en dólares. Escamilla (2015), El Complejo Industria Sahagún...capítulos II-IV.

6 Escamilla (2015), El Complejo Industrial Sahagún... capítulos II-IV. Un apunte interesante sobre este rezago de las tarifas y precios de venta de las empresas públicas frente al crecimiento de sus costos reales se encuentra en Izquierdo (1995), Política hacendaria del desarrollo estabilizador, 1958-1970; pp. 84-89.

7 Escamilla (2015), El Complejo Industrial Sahagún... capítulos IV y Epílogo. 


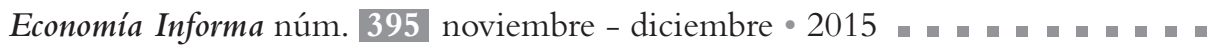

En este punto de la exposición surge la pregunta de por qué, a pesar de haber sido reconvertida, la empresa se terminó vendiendo en 1993. También parece importante precisar por qué fue la trasnacional canadiense Bombardier Inc., uno de los más destacados fabricantes de equipo aeronáutico y ferroviario en el mundo, la compañía que absorbió a la empresa mexicana. Si las empresas públicas no eran eficientes, tal como se repitió de manera incesante desde distintos ámbitos gubernamentales y por las asociaciones de empresarios privados durante las décadas de los años ochenta y noventa, ¿por qué pondría sus ojos en Concarril una firma tan experimentada y exitosa como Bombardier?

A raíz de estas inquietudes surgió una investigación paralela sobre Bombardier Inc. Tomando como base estudios y publicaciones de la Richard Ivey School of Business con sede en Ontario, Canadá, se encontró que la adquisición de Concarril obedece a una línea maestra que la compañía canadiense viene implementando desde los años ochenta - primero fue en Europa- para hacerse de activos estratégicos para su expansión comercial y de los avances tecnológicos desarrollados por sus competidores. ${ }^{8}$ En este sentido, la compra de la paraestatal mexicana estuvo fuertemente motivada por su desarrollo tecnológico alcanzado y, en particular, por el grado de innovaciones estratégicas incorporadas en varios conjuntos mecánicos de los trenes suburbanos fabricados en la planta de Ciudad Sahagún, Hidalgo, durante la década de 1980.

Por lo tanto, el primer objetivo de este trabajo es analizar ese otro aspecto de la compleja trama del proceso de privatización de Concarril y la industria de equipos ferroviarios en México, que no se limita sólo a la venta de las empresas públicas por sus malos resultados financieros, como lo ha querido acotar la ideología neoliberal, sino que escarba en el aspecto tecnológico y de mercado. El segundo propósito es señalar bajo este nuevo sentido la naturaleza y características del proceso de reestructuración de la industria de equipos ferroviarios en México a partir de su venta al capital extranjero.

\section{La expulsión de Concarril del negocio ferroviario y el ascenso de Bombardier-Concarril, 1992-1998}

Hasta ahora se tiene registrado que en 1992 Bombardier Transportation (la división ferroviaria de Bombardier Inc.), adquirió las instalaciones de la compañía estatal Constructora Nacional de Carros de Ferrocarril ubicadas en Ciudad Sahagún, Hidalgo, empresa que a partir de entonces se llamó Bombardier-Concarril S. A. de C. V.; y que se convirtió en el primer activo de

8 Escamilla (inédito), "Bombardier y Concarril: historias comparadas". 
la trasnacional canadiense en América Latina. No obstante, oficialmente la privatización se completó en $1994 .^{9}$

La historia de esta privatización puede dividirse para su estudio en tres etapas: a) la primera tiene sus antecedentes en la década de los ochenta, cuando Bombardier Inc., entró por primera vez al mercado mexicano, y se cierra aproximadamente en 1998, tiempo durante el cual las actividades de la compañía canadiense en México fueron principalmente estimuladas por la fabricación de trenes suburbanos y equipos para sistemas de transporte tipo "Metro"; b) en la segunda etapa, que inició alrededor de 1998, la producción de BombardierConcarril (BC) se diversificó para utilizar al máximo su capacidad productiva, mediante una serie de alianzas estratégicas con otras empresas fabricantes de equipos ferroviarios que atrajeron nuevas inversiones y elevaron a la planta hidalguense al plano internacional; c) la tercera etapa, que continúa hasta la fecha, surgió dentro de los cambios ocurridos durante la segunda etapa, pero arrancó con mayor claridad en 2006 (como respuesta a una crisis financiera que sacudió Bombardier Inc., en esos años) y se caracteriza por una importante restructuración de los activos de la compañía debido a una intensificación de las presiones competitivas que la llevan a implementar una estrategia de alianzas corporativas para no ver disminuida su cartera de clientes (aunque sus responsabilidades son cada vez más limitadas dentro de los nuevos contratos obtenidos).

Durante la década de los años ochenta la empresa estatal Concarril era fabricante de varios tipos de transporte ferroviario de carga, coches de pasajeros, carros tanque, trenes tipo metro y trenes suburbanos con rueda de acero; lo que fue posible debido a que sus instalaciones se encontraban diversificadas. Se contaba con 4 líneas de montaje, una para furgones, dos para otros equipos y una especial para el Metro; de igual forma, disponía de talleres para fabricación metálica ligera y pesada, pintura, carpintería y patio de pruebas, es decir, poseía una estructura productiva con un grado de integración vertical significativo.

También contaba con una red de proveedores locales considerable, comenzando por la propia Siderúrgica Nacional (otra empresa instalada dentro del Complejo Industrial Sahagún), que le suministraba acero en láminas y piezas forjadas (acopladores y trucks); y varias pequeñas empresas subcontratistas de procesos, principalmente del taller de fabricación metálica ligera,

9 Dentro de la publicación oficial de la Secretaría de Hacienda titulada Desincorporación de entidades paraestatales: información básica de los procesos del 1 de diciembre de 1988 al 31 de diciembre de 1993, México, julio 13 de 1994; el proceso de desincorporación de Concarril aparece "en proceso", sin mencionar en absoluto los concursantes, el monto estipulado y las condiciones de la venta. 
Economía Informa núm. 395 noviembre - diciembre • 2015 - "

que surgieron en la década de 1970 cuando la demanda de sus productos en algunos años rebasó la capacidad disponible. ${ }^{10}$

Además de sus competencias productivas, Concarril era la principal proveedora de equipos ferroviarios de carga y transporte en México, y sus principales clientes Ferrocarriles Nacionales de México y el Sistema de Transporte Colectivo Metro. En este contexto, el fabricante estatal además de poseer activos importantes era un competidor directo para otras empresas interesadas en atender la demanda interna de equipos ferroviarios, lo que convertía a Concarril en una empresa estratégica dentro de un mercado que además se proyectaba muy rentable para los siguientes años, por algunas razones que a continuación se exponen brevemente:

a) A fines de la década de 1980 se sabía públicamente que las autoridades de transporte de las dos mayores urbes del país, después del Distrito Federal, me refiero a Monterrey y Guadalajara, estaban preparando las convocatorias definitivas para el desarrollo de sistemas de transporte colectivos tipo "Metro". Por esos mismos años en la Ciudad de México se estaba terminando la ampliación y construcción de las líneas 7, 8 y 9 del Sistema de Transporte Colectivo (STC), así como la expansión al sur de la capital de una línea de tren ligero y otra al oriente con estructura férrea y catenaria (línea A); y ya se tenía proyectada la construcción de otra línea del Metro que llegaría hasta el Estado de México (que después se llamarían línea B). En este contexto, la adquisición de Concarril se hacía más atractiva por la posible adjudicación de estos contratos.

b) Los preparativos para la firma del Tratado de Libre Comercio con Estados Unidos y Canadá en 1992 vaticinaban un incremento en los flujos de transporte ferroviario entre los tres países. Más tarde, la desintegración y privatización de Ferrocarriles Nacionales de México a partir de 1995 incrementó significativamente la demanda de transporte de carga por motivo de la rehabilitación y reconversión de equipos emprendida por empresas extranjeras.

10 Secretaria de Energía, Minas e Industria Paraestatal (1987), CNCF, Informe de labores 1986-1987. Escamilla (2015), El Complejo Industrial Sahagún... capítulos III, IV y Epílogo. 
Este contexto explica en buena medida el interés de varias compañías por adquirir los activos de Concarril. Jacques Rogozinski, principal artífice del proceso de privatización en México, declaró hace poco tiempo en un entrevista en el noticiero de Carmen Aristegui, que cuando se realizaba el proceso de desincorporación de Concarril, a los dos meses de que salió la licitación oficial de venta, el Departamento del Distrito Federal emitió una convocatoria para rehabilitar varios trenes del Metro "entonces inmediatamente los que estaban compitiendo por Concarril me vinieron a decir que si ganaban, que si incluía el contrato del Metro". Rogozinski explica que la respuesta fue no, "porque una cosa es vender o licitar Concarril con un contrato, y una cosa es sin un contrato, por lo tanto los precios son diferentes ¿sí?, nadie se chupa el dedo". Supuestamente, dice Rogozinski, pese a quedar todo muy claro en el proceso de venta, los compradores de Concarril (Bombardier Transportation) "creo que también se enojaron mucho, es que dijeron: 'Es que nosotros creíamos que también nos iban a dar el contrato del Metro', y pues por escrito tenían que no era el caso". ${ }^{11}$

No obstante estas declaraciones, B-Transportation México reporta en documentos internos que en 1993 el Sistema de Transporte Colectivo Metro de la Ciudad de México le otorgó un contrato para la rehabilitación de 300 coches del metro; y en 1995 otro para la fabricación de 78 carros con rueda de acero para circular sobre la línea A. En este mismo año el Sistema de Transporte Eléctrico del D. F. (STE), le otorgó un contrato para la construcción de coches para el tren ligero. En 1993 Bombardier-Concarril también ganó la licitación para fabricar los trenes del Metro de Monterrey (Metrorrey) y para el Sistema de Tren Eléctrico Urbano de Guadalajara (siteur). En este sentido, todo apunta a que una de las razones que motivaron la adquisición de Concarril por parte de Bombardier se debió a la pugna por satisfacer la creciente demanda de equipos ferroviarios de transporte urbano en México.

Pero la puesta en venta de Concarril no sólo era atractiva por esta situación en el mercado. Lo que hacía más interesante su adquisición eran las adecuaciones técnicas y avances tecnológicos incorporados a los equipos que se fabricaban especialmente para el STC, a partir del prototipo original que fueron los primeros metros suministrados por la firma francesa Alsthom en los años setenta, y en el caso muy especial del desarrollo y construcción de un metro de rodadura férrea; que formaban parte de los activos físicos y el know how de la compañía estatal mexicana. Otra ventaja que tenía esta empresa era contar

11 Entrevista con Carmen Aristegui, MVS Noticias, 7 Julio de 2011. www.noticiasmvs.com [consultado en septiembre de 2013]. 


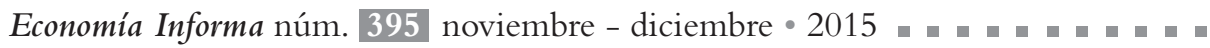

con una red de proveedores bastante extensa y especializada que permitió a Concarril la fabricación del metro con un grado significativo de integración productiva nacional.

De acuerdo con B. Navarro y Ovidio González, los primeros lotes de producción fabricados en las instalaciones de Concarril, entre 1974 y 1982, realizaron importantes modificaciones al diseño original de los equipos para el Metro, incorporando nuevos accesorios, mejoras a los sistemas mecánicos simples y cambiando algunos componentes por otros modelos más adecuados a las condiciones físicas de los túneles de la red del STC. De esta manera, se incorporó por primera vez a los trenes el convertidor estático, se modificó la distribución de los asientos para disponer de mayor espacio para los pasajeros de pie, se cambió el sistema de ventilación importado por otro elaborado localmente y el sistema de tracción y frenado JH se sustituyó por otro tipo "Chooper", lo que significó una innovación tecnológica directa a un sistema mecánico complejo aplicada por técnicos franceses y mexicanos que buscaban una forma más eficiente de recuperar la energía después del frenado. ${ }^{12}$

Cabe recordar que entre 1976-1984 se expandió notablemente la demanda de equipos para el STC "Metro", motivada por la construcción de las líneas 4, 56 y 7. Este boom del STC, en principio rebasó la capacidad instalada en Concarril, por tal motivo fue necesario contratar a otros fabricantes que, para cumplir con las especificaciones del STC e igualar los equipos que paulatinamente se hacían México, aplicaron las mejoras técnicas que Concarril desarrolló a partir de la primera serie de trenes para el metro (MP-68) fabricada por Alsthom en Francia, e integradas a la segunda y tercera serie fabricada en el país (NM-73 de 1974 y NM-79 de 1978). Estos fabricantes fueron Bombardier, en Canadá, para la serie NC-82 en 1982; Alsthom, en Francia, para la serie MP-82 en 1981 y Construcciones y Auxiliares Ferroviarios (CAF), en España, para la serie NE-92 en 1992 (para más detalle véase el cuadro anexo al final del capítulo).

De acuerdo con el Ing. Marcos Lechuga (ex empleado de Concarril), quien recuerda estos años y el modelo de los 180 carros fabricados por Bombardier en Canadá entre 1982-1985,

[...] el proveedor Bombardier empezó a surtir, con gran sorpresa nuestra, coches que contaban con los adelantos que la tecnología de los ingenieros de CNCF habían desarrollado y que lógicamente era propiedad del mismo Concarril. Bombardier nunca pagó regalías por el uso de tecnología mexicana $[\ldots] .{ }^{13}$

12 Navarro y González (1989), Metro, metrópoli, México; pp. 128-132.

13 Lechuga (inédito), Memorias. 
Cabe destacar que paralelo a este aumentó de las importaciones de coches del metro Concarril avanzaba vertiginosamente en la mexicanización de sus productos. En el tercer lote de producción, el NM-83 de 1983, se incluyó un secador de aire para el sistema neumático con base en tecnología de Concarril y se cambió la soldadura de resistencia por soldadura de electrodo. Estas mejoras en la estructura y componentes técnicos de los coches del metro surgieron, a decir de los investigadores arriba citados: "[...] de las reuniones técnicas que celebran dos veces por mes la CNCF y los representantes del STC-Metro". ${ }^{14}$ De tal manera que para 1984, 67\% de los componentes del tren tipo metro eran de origen nacional, muchos de ellos desarrollados a partir de las adecuaciones tecnológicas llevadas a cabo en Concarril:

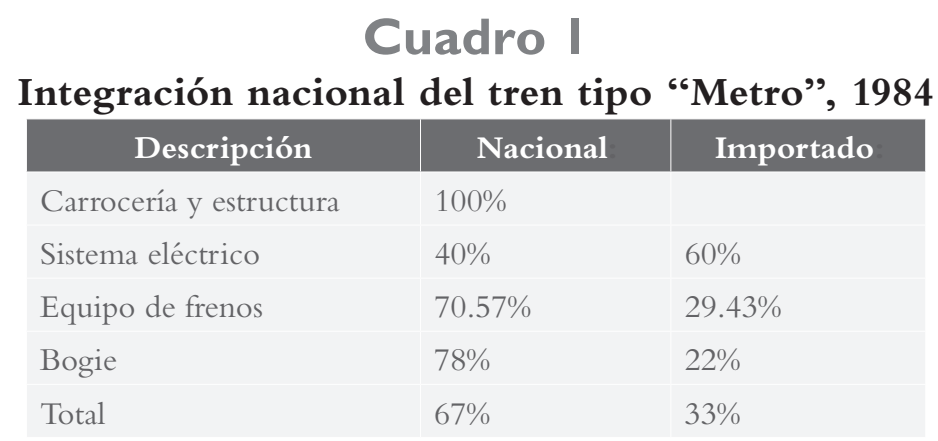

Fuente: Navarro y González (1989) Metro, metrópoli, México; p. 133.

No obstante, la fuente señalada constata que de los 268 proveedores nacionales con los que contaba Concarril en esos años, en 73 de ellos existía la participación de empresas transnacionales, por lo que cabe suponer que se trataban de empresas subsidiarias. Aun así, estos datos dan una idea acerca de la capacidad de eslabonamientos hacia atrás que inducía la fabricación del metro. ${ }^{15}$ Situación que se profundizó conforme avanzó la década. Para 1987, en los últimos carros pertenecientes a la serie NM-83 el grado de integración nacional ascendía a $76 \%$. De los insumos importados $22 \%$ correspondían al sistema eléctrico, 9.5\% al bogie y $1.3 \%$ al sistema de frenos. Respecto a la mexicanización del equipo de transporte ferroviario en general, el grado de integración nacional alcanzado para 1987 fue de 81\%, importándose única-

14 Navarro y González (1989), Metro, metrópoli, México; p. 132.

15 Navarro y Ovidio (1989), Metro, metrópoli, México; pp. 134-141. 


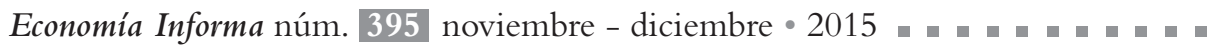

mente partes del sistema de frenos y algunos dispositivos especiales, dependiendo del producto. ${ }^{16}$

Todavía la última serie de coches tipo metro con rodadura neumática que se fabricaron para la línea 2 del sTC "Metro" entre 2002-2006 por Bombardier y CAF (quienes, como ya se dijo antes, auxiliaron a Concarril a principios de la década de 1980), incorporaron buena parte de los adelantos técnicos desarrollados en Concarril, aunque otros se superaron. La innovación más importante a partir de entonces se dio en el sistema de propulsión con la incorporación de motores asíncronos de corriente alterna en sustitución del ya mencionado Chopper (véase el cuadro anexo al final del capítulo).

Un caso que llama aún más la atención es el del metro con rodadura férrea, que es el que actualmente se utiliza en la recién inaugurada línea bicentenario del metro de la capital. Este producto se fabricó por primera vez en México en las instalaciones de Concarril en la década de los ochenta. De acuerdo con el informe de actividades de Concarril para los años 1986-1987, se firmó un convenio general de transferencia de tecnología y asistencia técnica entre Concarril y el fabricante ferroviario alemán FS/Duewag (comprado en 1989 por el consorcio Siemens), para el desarrollo y fabricación de trenes ligeros con rueda de acero, e inició el proceso de adquisición tecnológica y herramientas para la fabricación de bogies y articulaciones para estos trenes por un monto inicial de 132 millones de pesos. Al mismo tiempo se firmó con la empresa Brell (Inglaterra) un convenio general de colaboración para la fabricación de un nuevo tipo de coche de pasajeros llamado International Coach. Estas acciones permitieron a Concarril desarrollar nuevos productos: en 1986 se participó con un prototipo de monorriel para transporte interno en aeropuertos con dos o más terminales; en 1987 se presentó un modelo de metro ligero articulado para el sistema de transporte colectivo de la ciudad de Guadalajara (dos años más tarde se produjeron algunas unidades) ${ }^{17}$ y a partir de 1988 se inició la fabricación de 19 trenes eléctricos de rodadura férrea con catenaria para la línea A del STC, conocidos como la serie FM-86.

Justamente estas capacidades adquiridas por Concarril fueron absorbidas después por Bombardier quien siguió fabricando después de 1992 varias series de trenes ligeros para el STE (utilizados en la línea que va de Taxqueña a Xochimilco) y en 1995 la serie FM-95 de trenes de rodadura férrea con catenaria para la línea A del STC en colaboración con CAF, empresa que ha construido las últimas dos series de coches para el metro entre 2007-2012, la FE-07 y FE-

16 Secretaria de Energía, Minas e Industria Paraestatal (1987), CNCF, Informe de labores 1986-1987. 17 Secretaria de Energía, Minas e Industria Paraestatal (1987), CNCF, Informe de labores 1986-1987. 
10 (todos ellos con rodadura férrea y catenaria). Llama la atención que estas últimas tres series de metros férreos construidas por Bombardier y CAF tomen como punto de partida el modelo lanzado por Concarril entre 1987-1991 y recién las últimas dos incorporen innovaciones sustantivas al motor y los sistema de frenado y suspensión (para mayor detalle véase el cuadro anexo).

Regresando al análisis de la privatización y la conformación de Bombardier-Concarril en 1994, la información hasta ahora presentada permite observar la existencia de motivos comerciales y tecnológicos entre los factores que sustentan la adquisición de la empresa paraestatal por parte del consorcio canadiense: tanto para satisfacer la creciente demanda de equipos de transporte en México como para absorber los diseños y la tecnología de Concarril, incluso las mejoras técnicas que ésta aplicaba a productos de otras compañías (como Alsthom y FS/Duewag). En este sentido, con la compra de Concarril, Bombardier no reencauzó una empresa decadente. Por el contrario, la firma extranjera se benefició de la desaparición de una competidora directa y -tecnológicamente- de la adquisición de activos reconvertidos cuyo costo se endosó por completo al presupuesto público de la década de $1980 .{ }^{18}$

Por su parte, hacia 1995 la red de proveedores especializados con que contaba previamente Concarril se incrementaba (impulsados de igual manera por el boom de la demanda de transporte urbano en el país) y, a medida que se expandía la producción en los primeros años de las actividades de la firma canadiense en México, se hizo necesario integrar la producción de arneses eléctricos para abaratar costos y asegurar existencias, para lo cual se abrió dentro de la planta en 1998 una unidad especializada en la manufactura de esos componentes para todos los modelos que fabricaba la compañía. En este sentido, a fines de la década de 1990, la reconversión industrial iniciada en 1976 al parecer se mantenía encarrilada hacia algunas de sus metas originales brindando frutos (actualización tecnológica y desarrollo de nuevos productos competitivos en el mercado mundial), sin menoscabo importante de ciertos desarrollos alcanzados previamente, como la integración productiva con encadenamientos hacia atrás.

Sin embargo, estas continuidades y avances estuvieron acompañados de procesos subyacentes que en realidad significaron rupturas con respecto a ciertas tendencias de la etapa de industrialización previa. Como más adelante se

18 Y más adelante habrá que sacar cuentas para saber si el precio de venta de Concarril compensó esas inversiones, porque el tema aún no está claro y, de lo contrario, se estaría hablando de transferencias no reconocidas de recursos públicos al sector privado, con lo que el proceso de privatización adquiriría un significado muy diferente al que hasta ahora se le ha atribuido. 


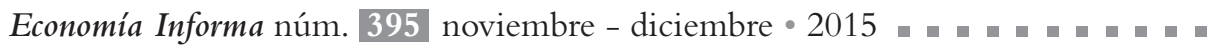

explica, las nuevas pautas productivas de la transnacional canadiense implican una constante vulnerabilidad económica externa que afecta principalmente a la red de proveedores locales, sobre quienes la empresa ha transferido paulatinamente los costos de mantener márgenes elevados de capacidad ociosa (por medio de un peculiar proceso de subcontratación); además de ello, ha crecido la precariedad laboral, acompañada de un discurso que públicamente responsabiliza de las contracciones productivas de la empresa a las exigencias $\mathrm{y}$ acciones por mejoras laborales.

Antes de continuar al siguiente apartado se presenta un cuadro resumen de la producción de Bombardier-Concarril entre 1992-1998, la cual se concentra esencialmente en equipos para transporte de pasajeros. Nótese la ausencia de producción de equipos de carga, división productiva original de Concarril y en la cual se contaba con el mayor grado de integración productiva vertical (y por tanto de mexicanización) así como de diversificación de productos durante la década de los ochenta. Esto se debe a que en estos años se marginó casi por completo esta división productiva (curiosamente, la razón original de esta empresa), ocasionando que las instalaciones de Bombardier-Concarril presentaran una elevada subutilización. He aquí un sólido caso de desindustrialización (parcial).

\section{Cuadro 2}

Producción de Bombardier-Concarril, 1992-1998

\begin{tabular}{|c|c|c|}
\hline Año & Producto & Cliente \\
\hline 1993-1995 & 62 Vehículos de tren ligero & Metrorrey (Monterrey) \\
\hline 1993-1994 & 48 Vehículos de tren ligero & SITEUR (Guadalajara) \\
\hline $1993-2000$ & Rehabilitación 60 trenes (540 vehículos) & STC (Ciudad de México) \\
\hline 1995-1998 & 78 vehículos tipo metro de rodadura férrea con catenaria & STC (Ciudad de México) \\
\hline 1998-1999 & 4 Trenes ligeros & STE ( Ciudad de México) \\
\hline 1998 & Arneses para modelos en fabricación o rehabilitación & Bombardier-Concarril \\
\hline
\end{tabular}

Fuente: Elaboración propia con base en Bombardier Transportation (2013), Hoja de datos de planta.

\section{Primera fase del proceso de reestructuración (1998-2002): diversificación productiva}

A fines de 1997 se agotaba la bonanza que trajo consigo la fabricación de trenes tipo metro. Por otra parte, la compañía española CAF, socia de Bombardier para algunos proyectos en América Latina y en la fabricación de 78 vehículos de rodadura férrea con catenaria para el STC "Metro" en 1995, incrementaba 
su presencia en México e intensificaba las presiones competitivas en el mercado de equipos ferroviarios de transporte para pasajeros. Por tales motivos Bombardier-Concarril se vio en la necesidad de restructurar su oferta productiva y aligerar su pesada carga de instalaciones inutilizadas.

Bajo este contexto, en 1998 Bombardier-Concarril estableció un contrato con la firma Electro-Motive Diesel Inc. (EMD), filial de la estadounidense Progress Rail Services Corporation, para fabricar partes y ensamblar locomotoras diésel-eléctricas en la planta de Ciudad Sahagún, producción que hasta 2014 alcanzaba 2000 unidades. Una fuente establece que los menores costos de producción en México propiciaron que en marzo del año 2000 EMD cerrara su planta en La Grange, Illinos, Estados Unidos. ${ }^{19}$

Pero el proyecto más interesante fue el establecimiento en 1998 de una Joint venture ${ }^{20}$ llamada Gunderson-Concarril con el más importante fabricante de barcazas marinas, equipos ferroviarios y terrestres de carga en Estados Unidos, The Greenbrier Companies, para la fabricación y reparación de furgones, plataformas, góndolas, tolvas y otros equipos de carga, así como componentes y material rodante. El motivo de esta alianza se debe al aumento de la demanda de equipos ferroviarios a medida que los activos de Ferrocarriles Nacionales de México eran adquiridos por compañías norteamericanas (entre 1995-1998); mismas que realizaron inversiones para rehabilitar la red ferroviaria nacional y su parque vehicular. ${ }^{21}$

No deja de ser curioso, y un tanto irónico, que la misma razón por la que fue creada Concarril en 1952 esté presente en la privatización de Ferrocarriles Nacionales de México: la rehabilitación de su parque vehicular. Cabe destacar que como parte de la Joint venture, Bombardier-Concarril compartió sus activos e instalaciones, en espera de que Greenbrier aportara su experiencia y habilidades en el ramo. En su página web, ésta última menciona que las instalaciones de Bombardier-Concarril que encontró en 1998 eran de primera

19 Véase Guajardo (2010), "La industria de equipos ferroviarios en México"; p. 20.

20 Alianza estratégica entre dos compañías que da pie a una tercer empresa conjunta, la razón principal de formar un Joint venture es unir conocimientos, aptitudes y recursos, compartiendo a su vez las ganancias y los riesgos. Sus integrantes mantienen su identidad e independencia corporativa, no existe ni fusión ni absorción para implementar el acuerdo.

21 A decir verdad, la infraestructura ferroviaria no ha crecido desde su privatización; mientras que el volumen de la carga transportada, principalmente hacia México (es decir, volumen de carga importada), sí ha crecido, ocasionando una saturación de la capacidad de transporte instalada. En este sentido, las inversiones privadas se han concentrado en la rehabilitación del equipo rodante de carga, pues el servicio de transporte de pasajeros ha caído estrepitosamente. Por su parte, el personal empleado en las líneas ferroviarias ha disminuido drásticamente y su productividad, medida en unidades de tráfico por empleado, ha crecido súbitamente. Medina Ramírez (2013), "El transporte ferroviario en México". 
Economía Informa núm. 395 noviembre - diciembre • 2015 - "

calidad. ${ }^{22}$ En 2004 Greenbrier adquirió los intereses de Bombardier en la joint venture Gunderson-Concarril, inaugurando así otro capítulo en la historia de la fabricación de equipos ferroviarios en México. Dos años después, la trasnacional estadounidense conformó la compañía Gunderson-GIMSA S. de RL de $\mathrm{CV}$, una joint venture con el Grupo Industrial Monclova, para la fabricación de furgones y otros equipos.

Al mismo tiempo que Bombardier-Concarril diversificaba su producción, sacando provecho de sus activos adquiridos en 1992, se rehabilitó una faceta productiva que la empresa paraestatal había desarrollado desde los años sesenta, la proveeduría a otros fabricantes. El lugar que en su momento ocupó Diésel Nacional y Siderúrgica Nacional, como clientes para la producción de bastidores, carrocerías y piezas de tractor, lo vinieron a ocupar otras empresas dentro de la red de Bombardier Transportation. De esta manera, a partir de 1999 Bombardier-Concarril comenzó a proveer componentes destinados a diversos proyectos de la corporación en Estados Unidos; y en 2000 se inició la fabricación de bastidores para carros del metro de New York City Transit.

\section{Segunda fase del proceso de reestructuración: alianzas estratégicas en un contexto de crisis, 2002-2012}

En 2001, las autoridades del transporte colectivo de la Ciudad de México emitieron una convocatoria para la fabricación de 45 trenes de rodadura neumática de nueve vehículos cada uno, destinados a atender el aumento de la demanda de servicios en el metro de la Ciudad de México. Esta fue la primera convocatoria para fabricar trenes del metro después de casi diez años, donde Bombardier y otras empresas de nivel internacional participaron, siendo ganadora la propuesta de colaboración conjunta entre CAF y Bombardier-Concarril. Ésta última empresa fue responsable de la construcción de 28 trenes y el diseño y fabricación de 810 bogies entre 2002 y 2004; los carshells y diseños de trenes se desarrollaron conjuntamente con la compañía española. Esta fue la primera de una serie de alianzas estratégicas que la subsidiaria de la canadiense en México ha implementado desde entonces para poder mantener activas tanto su cartera de clientes como su capacidad instalada.

Como parte de este proceso, a partir de 2004 se incrementó la fabricación de componentes primarios, sub-emsables menores, arneses eléctricos, truks y sistemas de tracción para proyectos ferroviarios de riel ligero y suburbanos, de Bombardier Transportation en Estados Unidos y Canadá, con New Jersey 22 http://www.gbrx.com/About_us [consultado en Noviembre de 2013] 
Authority Transit, Agence Métropolitaine de Transport (Montreal), Chicago Transit Authority, Toronto Transit Comission, Mineapolis Transit Authority, New York City Transit y Bay Rapid Transit en San Francisco, Califronia. ${ }^{23}$

Derivado de esta especialización productiva en 2009 se trasladó la división de arneses eléctricos de la planta de Ciudad Sahagún a una planta manufacturera recién inaugurada en Huehuetoca, Edo. México, que actualmente es la principal proveedora de Bombardier Transportation en América del Norte. ${ }^{24}$ Es importante mencionar que México ocupó el segundo lugar a nivel mundial en la exportación de arneses y conductores en 2014, por debajo de China. Del total, la producción destinada a la industria ferroviaria, aeroespacial y eléctrica constituye $40 \%$. El objetivo, de acuerdo con una entrevista al representante en jefe de Bombardier México, Alfredo Nolasco, es que México se convierta en un "centro mundial de excelencia de arneses", para ello se plantea la posibilidad de trasladar la producción de arneses ferroviarios que se realiza en Polonia y Austria a México, tal como se transfirió en 2006 la producción de arneses para avión de Japón a México. ${ }^{25}$

Esta capacidad de relocalización de funciones dentro del entramado global de la empresa ha beneficiado al país, en particular a Querétaro y Ciudad Sahagún, donde la multinacional tiene las sedes productivas de sus divisiones Aeroespace y Transportation Mexico. Sin embargo, las mismas medias han generado inestabilidad laboral en otras partes del mundo. Tan sólo entre 2001 y 2004 Bombardier recortó cerca de 7500 puestos de trabajo en Europa, cerró 9 plantas productivas y transfirió capacidades de fabricación instaladas en Europa y Canadá hacia otras partes del mundo, principalmente a México. ${ }^{26}$ Sucesivas olas de despidos y relocalizaciones en los últimos diez años han acompañado el crecimiento de las actividades de Bombardier en nuestro país.

23 Bombardier Transportation (2013), Más de veinte años en México. Bombardier Transportation (2013), Hoja de datos de planta. En varios documentos la compañía expone que la planta de Ciudad Sahagún "apoya la estrategia global de fabricación", rol que, en efecto, cada vez más define los intereses de la trasnacional en México. En 2000 se construyeron bastidores para el metro de la ciudad de Nueva York; en 2004 se fabricaron bastidores para el Long Island Rail Road (LIRR) y MNR; en 2006 se armaron partes primarias, subconjuntos, arneses y bastidores de bogie para los metros de New Jersey, Montreal, Chicago, Toronto. En 2012-2013 se fabricaron trucks, bolsters, bastidores, arneses y partes primarias para el BART de San Francisco, California. A diferencia de los contratos donde figura como líder de proyecto, en los arriba mencionados el papel de Bombardier-Concarril es más parecido al de un proveedor especializado, en ocasiones intrafirma, pero en otras en alianza estratégica con otras compañías competidoras en el ramo. Bombardier Tnasportation Mexico (2015), Bombardier, la experiencia de invertir en Hidalgo.

24 Ídem.

25 El economista (2-06-2015), "México liderará producción de arneses de Bombardier".

26 El país (14-11-2001), "Bombardier cerrará tres fábricas y prevé 1050 despidos”. El país (18-02-

2004), "Bombardier recorta 6600 empleos y cierra siete plantas en Europa". El País (2-12-2004),

"Nuevos despidos masivos en Deutsche Bank y Bombardier". 
Economía Informa núm. 395 noviembre - diciembre • 2015 - "

Pero esta vez una nueva ola de recortes masivos de la compañía que actualmente azota a varios países en el mundo ha incluido a México. ${ }^{27}$ Sobre este tema se regresará más adelante.

Retomando la cuestión productiva, los últimos contratos donde Bombardier Transportation México aparece como fabricante principal (hasta 2012) han sido para la construcción de 188 carros de trenes Advance Rapid Transit (ART) para Vancouver y Kuala Lumpur, Malasia, entre 2006-2008; y en 2012, para el diseño, la manufactura y la puesta en servicio de 4 trenes ligeros para el STE de la ciudad de México. ${ }^{28}$ Esta restructuración ha traído consigo la pérdida de relevancia de la compañía canadiense en México, que se refleja en los dos últimos contratos para fabricar trenes para el STC de la ciudad de México (2007-2012), que fueron adjudicados a la española CAF.

Pero también, esta flexibilidad productiva que muestra la subsidiaria de Bombardier en México, tanto para aparecer como fabricante principal, participante secundario, proveedor intra-firma o como simple proveedor y auxiliar en proyectos de otras corporaciones, muestra la intensificación de una peculiar forma de integración productiva en matriz, es decir, múltiples combinaciones verticales-horizontales de producción flexible y en tiempo real a nivel de grandes firmas, bajo la apariencia de alianzas estratégicas que les permiten a éstas diversificar riesgos, compartir información, satisfacer necesidades en tiempo record y relocalizar su producción con mayor rapidez, así como brindar servicios de mantenimiento y posventa en casi cualquier parte del mundo. Se trata de una auténtica red global de producción, en la que activos instalados, como los de Querétaro y Ciudad Sahagún, a pesar de su solidez productiva, son piezas intercambiables subordinadas a las constantes reestructuraciones de los objetivos globales de la firma trasnacional, cuya competencia frente a otras compañías adquiere distintas facetas.

Guillermo Guajardo, investigador del CIIH, UNAM, quien es de los pocos que estudian la industria de equipos ferroviarios en México, señala que estas acciones forman parte de una estrategia para mejorar la integración de la producción de Bombardier Transportation en Norteamérica y su competitividad frente a otros poderosos consorcios. ${ }^{29}$ Agregaría que estas medidas también sirven tanto para reducir riesgos de acumular altos márgenes de capacidad

27 CNNEXPANSIÓN (15-01-2015), "Bombardier despedirá a 380 empleados en Querétaro". AFP (14-05-2015), "Cuarta ola de despidos en Bombardier en 18 meses". CNNEXPANSIÓN (14-05-2015), "Bombardier recortará 1750 puestos de trabajo".

28 Ídem.

29 Guajardo (2010), "La industria de equipos ferroviarios en México”; p. 21. 
ociosa en todos sus activos, en momentos de fuertes contracciones en los mercados de sus productos, como para reducir costos laborales.

Esto conduce a la parte final de este avance de investigación: las capacidades instaladas en Bombardier Transportation México, la relación con sus proveedores y la fuerza de trabajo, y su forma de reaccionar frente a caídas en las ventas, temas que definirían una parte del perfil actual del comportamiento de esta transnacional en el país.

\section{Alcances, contradicciones y límites de la nueva estrategia productiva en la industria de equipos ferroviarios}

\section{Reconversión industrial}

La reconversión industrial en Concarril comenzó desde fines de década de los años setenta bajo la conducción del Estado. Aunado a las inversiones, desarrollos tecnológicos y acuerdos de colaboración técnica con fabricantes ferroviarios extranjeros para la fabricación del metro, el tren ligero y la elaboración de varios prototipos de productos (que se describió en el apartado 1 de este trabajo), en 1987 se adquirió tecnología de General Motors para la rehabilitación, modernización y fabricación de locomotoras; del mismo modo se comenzó la habilitación de una sexta línea de ensamble para estos equipos. ${ }^{30}$

Sobre esta base tecnológica -cuyo éxito productivo quedó empañado por el deterioro financiero que padeció durante buena parte de su existencia-, Bombardier Transportation fincó un proceso de modernización, que más bien fue de continuidad con ciertas pautas establecidas previamente, tal como lo muestra la fabricación y rehabilitación de equipos para metro y tren ligero entre 1992-1998, que se basan en los productos elaborados por Concarril antes de su privatización.

La aportación de Bombardier Transportation a este proceso radica en la trasferencia de tecnologías ferroviarias adquiridas de otras compañías incorporadas al consorcio durante las dos décadas finales del siglo xx, que han permitido innovaciones importantes a los sistemas complejos de estos equipos y la incorporación de los nuevos servicios automatizados. A ello se suman los acuerdos productivos y alianzas estratégicas (Joint ventures) establecidas con otras compañías competidoras que modernizaron aún más ciertos activos de

30 Secretaria de Energía, Minas e Industria Paraestatal, CNCF, Informe de labores 1986-1987, México, 1987. 


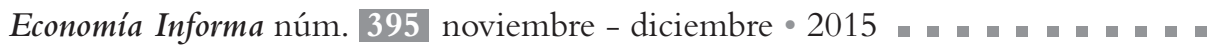

Bombardier-Concarril que no se utilizaban eficientemente, como las líneas de montaje de equipo rodante de carga y locomotoras.

De esta forma, a partir de la primera década de este nuevo siglo en las instalaciones de la otrora empresa paraestatal se tienen capacidades para fabricar toda clase de vehículos tipo metro, con rodadura de neumático o rodadura férrea; trenes ligeros, trenes regionales y locomotoras; así como subconjuntos menores y mayores para estos equipos en todos -los diferentes entre sí- proyectos que tiene la firma en Norteamérica y en varias partes del mundo; y también furgones, carros góndola y plataformas que construyó a gran escala Gunderson-Concarril (como se llamó hasta fechas recientes la Joint venture firmada en 1998). ${ }^{31}$

Proveedores de esta compañía establecen que la planta está equipada con maquinaria de última generación para la manufactura de todos sus productos y servicios; y opera con capacidades de ingeniería y manufactura de ciertos procesos integradas (es decir, controladas exclusivamente por la firma). La firma, en su hoja de datos de planta presenta las siguientes instalaciones con las que cuenta; cabe destacar, sin embargo, que la mayoría ya estaban antes de 1992 y fueron desarrolladas por Concarril en diversas ampliaciones y restructuraciones que realizó desde 1959 (las que tienen el asterisco):

\section{Tabla I}

\section{Instalaciones Bombardier Transportation México 2012}

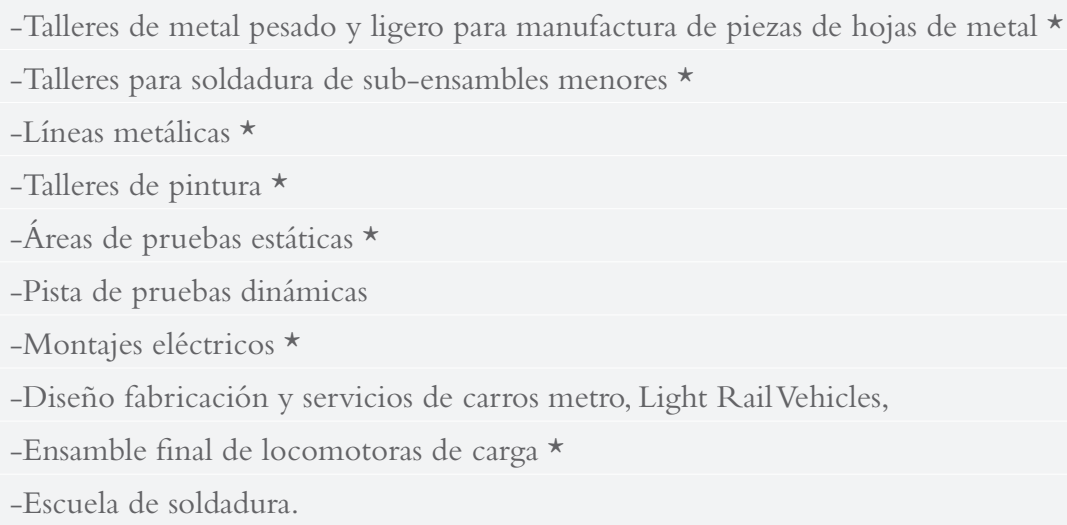

Fuente: Bombardier Transportation (2013), Hoja de datos de planta. Los antecedentes de estas instalaciones son de elaboración propia con base en diversos informes de la compañía al $\mathrm{H}$. Consejo de Administración.Véase Escamilla (2015), El Complejo Industria Sahagún (1952-1995).

31 Cabe mencionar que esta última empresa dio por terminado en 2014 los contratos de arrendamiento de las instalaciones que tenía con Bombardier-Concarril desde 2004, y transfirió parte de su producción al estado de Tlaxcala. Una filial suya,YSD Doors S. A. de C.V., mantendrá la producción de partes metálicas para plataformas, góndolas y furgones en Ciudad Sahagún. Esta trama, al igual que la Bombardier Transportación, encierra un proceso de desindustrialización parcial y latente, resultado de la atomización de capacidades productivas con base en una espesa red de filiales y sub- 
Otro aspecto importante dentro de esta reconversión son las certificaciones con las que cuenta las empresa: ISO 9001:2008 (Sistemas de Administración de Calidad), ${ }^{32}$ ISO 14001:2004 (Sistema Ambiental), ${ }^{33}$ OHSAS 18001:2007 (sistema de higiene y seguridad) ${ }^{34}$ y también está avalada por la American Welding Society ${ }^{35}$ y la American Association of Railroads. ${ }^{36}$ Estas certificaciones son exigidas por todos los clientes privados y gobiernos dentro de los concursos y licitaciones de fabricación. Para mantenerse en ellas es necesario atender sus indicaciones y reconvertir constantemente procedimientos, normas y especificaciones. En realidad, estas certificaciones actúan como una especie de barrera de entrada al negocio de la construcción de equipos ferroviarios, pues quien no cuenta con ellas queda fuera de la mayoría de licitaciones que se efectúan en varios países. Estos procedimientos también son aplicados a la red de proveedores locales. ${ }^{37}$

32 Se trata de una norma internacionalmente aceptada para establecer sistemas de gestión de calidad (SGC). La norma está diseñada para incrementar la calidad en los productos de cualquier empresa mediante diversos métodos, para cumplir con las legislaciones en materia de calidad y satisfacción al consumidor local e internacionales, sin menoscabo de la rentabilidad de una empresa [traducción propia] www.iso.org [consultado en noviembre de 2013].

33 Se trata de una norma internacionalmente aceptada para establecer sistemas de gestión ambiental (SGA) efectivos. La norma está diseñada para reducir de los impactos ambientales y cumplir con las legislaciones en materia ambiental locales e internacionales, sin menoscabo de la rentabilidad de una empresa [traducción propia] www.iso.org [consultado en noviembre de 2013].

34 Se trata de una norma internacionalmente aceptada para establecer sistemas sistema de gestión de la salud y la seguridad en el trabajo. La norma está diseñada para reducir los accidentes y preservar la salud en el trabajo en el marco de las respectivas legislaciones en materia laboral locales e internacionales, sin menoscabo de la rentabilidad de una empresa [traducción propia] www.ohsas.org [consultado en noviembre de 2013].sistema de gestión de la salud y la seguridad en el trabajo

35 Organismo internacional de investigación para tecnologías aplicadas a la soldadura y procesos de unión y corte de aliados, incluyendo la proyección térmica. Lleva a acabo procedimientos de código y certificación, que proporcionan los estándares industriales para la soldadura y unión de metales, plásticos y otros materiales. A través de sus publicaciones, foros, eventos, recursos educativos y actividades de networking, AWS mantiene a los profesionales de soldadura y los interesados en la ciencia de los materiales al día con los avances y procedimientos más actuales en la industria [traducción propia]. www.aws.org/ [consultado en noviembre de 2013].

36 LaAsociación de Ferrocarriles Americanos (AAR) es un organismo que representa los intereses de las principales compañías ferroviarias de carga de América del Norte (Canadá, México y Estados Unidos). trabaja para mejorar la eficiencia, la seguridad y el servicio de la industria del ferrocarril, así como las normas de eficiencia y especificaciones de los equipos ferroviarios [traducción propia] https:// www.aar.org/ [consultado en noviembre de 2013].

37 Bombardier Transportation (2013), Más de veinte años en México. Bombardier Transportation (2013), Hoja de datos de planta. 
Economía Informa núm. 395 noviembre - diciembre • 2015 - "

Relación con proveedores:

nuevas formas de evitar la acumulación de capacidad ociosa

En un libro de reciente aparición sobre la industria aeroespacial en México se establece, entre otras conclusiones, que una de las principales razones por las que Bombardier Aeroespace decidió instalar en Querétaro, en 2006, una planta para el armado de fuselajes traseros y alas para varios de sus modelos, así como la fabricación de distintos sub-ensambles, de todo el paquete de control de vuelo (rudder, elevador y estabilizadores horizontal y vertical) y arneses eléctricos, fue la red de proveedores nacionales y extranjeros localizados en el país, principalmente en tres parques industriales tipo clústeres en Querétaro, Baja California y Chihuahua. Esta red, en conjunto con otros dos factores importantes: las características de la mano de obra en México (calificada y barata) y la concentración de las ventas de la División Aerospace en América; ha propiciado que la corporación transfiera casi todas las actividades desde su planta de Belfast, Irlanda, a México. ${ }^{38}$

Como se mencionó en el apartado anterior, esta capacidad de relocalización de activos y funciones, que también está presente en su división Transportation, responde a una estrategia de integración productiva vertical-horizontal derivada del aumento de las presiones competitivas entre grandes fabricantes ferroviarios a nivel mundial en un contexto de crisis generalizada; estrategia que tiene como objetivo reducir costos laborales y hacer frente a las necesidades cambiantes y específicas que tiene la demanda de estos productos. Existen condiciones objetivas que permiten dicha restructuración, tales como la flexibilidad tecnológica e institucional (relajamiento de las leyes de inversión extranjera, de regulación del trabajo y medidas ambientales, entre otras).

La nueva organización productiva derivada de estos cambios consiste en que la compañía extranjera instala, adquiere o refuncionaliza activos para desarrollar una capacidad de manufactura bajo su control (integración vertical), mediante la cual se reduce su dependencia de terceros para obtener componentes estructurales de las aeronaves y otros productos. De esta manera, se reducen significativamente costos operativos e incertidumbres en el abastecimiento de ciertos insumos. Al mismo tiempo, la compañía fomenta y patrocina el surgimiento de una red de proveedores altamente especializados, a los cuales, en ocasiones certifica y capitaliza (integración horizontal), incluso otorgándoles la materia prima (moderno putting-out system). Esta producción dispersa (en talleres de propiedad particular), no consiste sólo en 38 Casalet (2013), La industria aeroespacial. 
la fabricación de componentes y materias primas específicas, muchas de estas pequeñas empresas en realidad son subcontratistas de servicios y procesos de fabricación compleja. Esta estrategia aminora los riesgos para la firma extranjera de acumular capacidad ociosa en periodos de fuertes contracciones de ventas o crisis económicas, transfiriéndolos directa e indirectamente a sus proveedores y subsidiarias. ${ }^{39}$

Bombardier-Concarril se instaló en el Complejo Industrial Sahagún aprovechando la red de proveedores altamente especializados desarrollada por Concarril desde los años setenta. A inicios de la década de los noventa Plásticos Automotrices Dina (más tarde Plásticos Automotrices Sahagún) y Siderúrgica Nacional (a partir de 1995 ABC-National Casting Co y en 2005 ASF-Keyston) conformaban la columna vertebral de la red de proveedores de la empresa paraestatal. A la llegada de Bombardier ésta trama diversificó aún más, debido a la inestabilidad de las dos empresas antes mencionadas, pero también a causa de una estrategia de flexibilización productiva que, en concreto, consiste en desconcentrar activos dedicados a procedimientos principalmente al detalle para diversificar riesgos (i. e. maquinados de piezas, subensambles de partes, soldaduras y acabados).

La estrategia está motivada por el aumento de la cartera de clientes, productos y servicios que ofrece Bombardier-Concarril sobre todo a partir de 1999. Hacia 2013 Bombardier Transportation contaba con una red aproximada de 10 proveedores y subcontratistas locales, ubicados principalmente dentro del ramo metalmecánico ferroso y no ferroso, que fabricaban para la compañía diversas piezas y partes al detalle, así como soldaduras especiales de componentes e, incluso, acabados de interiores en la propia planta. Para mayor detalle obsérvese el cuadro 3.

El caso del proveedor más importante de los 10 enlistados, Global Transporte Industria y Servicios S. A., ilustra un patrón que se repite en los demás y que permite acercarse a la forma en que Bombardier va integrando su producción horizontalmente a partir del proceso de privatización de Concarril. Esta empresa local (instalada en una colonia habitacional), surgió en 1991 como una sociedad creada por ingenieros, técnicos y obreros del área de diseño e inge-

39 Tal como lo comprobó la compañía en la década de 1970. A principios de esta década la empresa canadiense realizó importantes inversiones para integrar verticalmente su división de motonieves, sostenidas en altas expectativas de demanda. El shok petrolero de la década redujo drásticamente los niveles de venta de sus productos y con ello, la compañía acumuló enormes inventarios y capacidad ociosa que incrementó notablemente sus costos de producción. A partir de esta experiencia la empresa comenzó a desconcentrar activos. Escamilla (inédito), "Bombardier y Concarril: historias comparadas". 
Economía Informa núm. 395 noviembre - diciembre • 2015 - "

niería industrial de Concarril con más de veinte años de trayectoria, y que con base en sus conocimientos adquiridos sobre el proceso de fabricación de los trenes tipo metro y el dinero de sus liquidaciones decidieron instalar una empresa fabricante de componentes especiales metálicos y de fibra de vidrio, que incluye servicios de diseño, acabados y mantenimiento. Una vez que Bombardier se hizo del contrato de rehabilitación de los 60 primeros trenes del metro entre 1993-2000 al mismo tiempo que fabricaba trenes ligeros para el D. F., Monterrey y Guadalajara entre 1993-1997, inició un proceso de subcontratación de servicios para satisfacer su cartera de clientes. Aquí comenzó la relación entre la compañía y Global Transporte: Bombardier aprovechaba la experiencia de su proveedor en el ramo, pero principalmente los conocimientos al detalle sobre el funcionamiento y equipamiento de los equipos por rehabilitar. ${ }^{40}$

La eficiencia de Global Transporte lo ha llevado a ser contratado por Bombardier Transportation México en diversas ocasiones, no sólo para proyectos nacionales sino también para la proveeduría en proyectos de toda Norteamérica. Incluso, a finales de la década de los noventa, Global Transporte comenzó a diversificar su cartera de clientes nacionales, que actualmente abarca el Sistema de Transporte Colectivo Metro (rehabilitaciones), DINA camiones (partes, frentes y laminación exterior), Arteche Tecnología (partes de acero inoxidable para estaciones eléctricas de baja, media y alta tensión), Aeropuertos y Servicios Auxiliares (contenedores, equipo para mantenimiento y limpieza en terminales), Comesa S. A. (Dormitorios prefabricados), entre otros. La pequeña empresa hidalguense también atende clientes internacionales como Bombardier Trasnportation Norteamérica y Alsthom, Francia (acabados de interiores, bastidores, casetas, platinas, gabinetes de control y componentes para la rehabilitación de sus equipos vendidos en México). ${ }^{41}$

40 Información obtenida con base en trabajo de campo y en su sitio web http://www.global-tis. com/ [consultado en noviembre de 2014].

41 Ídem. 


\section{Cuadro 3}

\section{Proveedores y prestadores de servicios locales de Bombardier Trasnportation México (estimado)}

\begin{tabular}{|c|c|c|c|c|}
\hline Empresa & Ramo & Tamaño & Productos y servicios & Capital \\
\hline $\begin{array}{l}\text { Global transporte } \\
\text { industria y servicios }\end{array}$ & $\begin{array}{l}\text { Metalmecánica ferrosa } \\
\text { y no ferrosa }\end{array}$ & Mediana & $\begin{array}{l}\text { Elaboración de interiores para ca- } \\
\text { rros tipo Metro en fibra de vidrio } \\
\text { y acero inoxidable, traversas para } \\
\text { puentes de bogie }\end{array}$ & Nacional \\
\hline Maquinados Teysa & Metalmecánica ferrosa & Microempresa & $\begin{array}{l}\text { Maquinados de partes ferroviarias } \\
\text { y acabado de piezas de fundición }\end{array}$ & Nacional \\
\hline $\begin{array}{l}\text { Equipos y soldaduras } \\
\text { Hiromi }\end{array}$ & Metalmecánica ferrosa & Microempresa & Soldaduras especializadas & Nacional \\
\hline $\begin{array}{l}\text { Maquinados } \\
\text { Industriales }\end{array}$ & Metalmecánica ferrosa & Microempresa & $\begin{array}{l}\text { Fabricación de piezas metálicas, } \\
\text { mecánicas y especiales en general }\end{array}$ & Nacional \\
\hline Industrial Sahagún & Metalmecánica ferrosa & Pequeña & $\begin{array}{l}\text { Fabricación de piezas y productos } \\
\text { a diseño a partir de distintos tipos } \\
\text { de acero }\end{array}$ & Nacional \\
\hline Maquinados reyes & Metalmecánica ferrosa & Microempresa & $\begin{array}{l}\text { Maquinados especiales y servicios } \\
\text { de soldadura }\end{array}$ & Nacional \\
\hline $\begin{array}{l}\text { Ferretera industrial } \\
\text { y de servicios } \\
\text { hidalgo }\end{array}$ & Metalmecánica ferrosa & Microempresa & $\begin{array}{l}\text { Maquinado industriales conven- } \\
\text { cionales y de control numérico, } \\
\text { troquelados, cortes especiales sol- } \\
\text { daduras especiales, paileria, diseño, } \\
\text { fabricación de dispositivos y man- } \\
\text { tenimiento. }\end{array}$ & Nacional \\
\hline $\begin{array}{l}\text { Metal-mecánica } \\
\text { integral }\end{array}$ & Metal mecánica ferrosa & Pequeña & $\begin{array}{l}\text { Maquinados especiales y servicios } \\
\text { de soldadura }\end{array}$ & Nacional \\
\hline $\begin{array}{l}\text { Construcciones } \\
\text { y proyectos Herco }\end{array}$ & Servicios & Microempresa & $\begin{array}{l}\text { Construcciones y renta de maqui- } \\
\text { naria para la construcción }\end{array}$ & Nacional \\
\hline SISAC & Servicios & Pequeña & $\begin{array}{l}\text { Servicios de mantenimiento in- } \\
\text { dustrial }\end{array}$ & $\mathrm{Na}$ \\
\hline
\end{tabular}

Fuente: elaboración propia con base en trabajo de campo y sitios web de algunas empresas, a partir del directorio www.isac.tepeapulco.gob.mx [septiembre-noviembre de 2013].

Estas características observadas en Global Transporte: empresa creada por ex empleados y obreros, vinculada inicialmente como proveedora de la empresa donde antiguamente laboraban aquellos, y que posteriormente diversifica su cartera de clientes; es un patrón observable en la mayoría de las empresas descritas en el cuadro de arriba y muestra una tendencia que se deriva de la forma en cómo Bombardier-Concarril integra su producción.

Con el objetivo de disminuir costos, cuando surge un proyecto de fabricación con características especiales exigidas por el cliente, que implicarían inversiones dentro de la planta para el diseño y desarrollo de piezas o sub- 


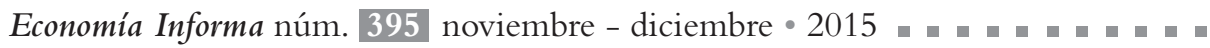

ensambles especiales, la compañía extranjera contrata proveedores locales altamente especializados y subcontrata empresas, también locales, para realizar procesos; de esta forma la firma trasnacional no integra activos que posteriormente podrían elevar sus márgenes de capacidad ociosa cuando otros clientes soliciten nuevas especificaciones que impliquen otro tipo de maquinaria y procesos. Esta estrategia también permite diversificar rápidamente sus productos o relocalizar su producción a otros sitios cuando suceden fuertes caídas en sus ventas, simplemente sustituyendo su red de proveedores que sobrevive, si bien le va, consiguiendo otros clientes.

Esta es la base de la nueva integración productiva en matriz, que se complementa con el resguardo en la corporación de los procedimientos más complejos y con alto valor tecnológico (diseño de productos, sistemas complejos, procedimientos exclusivos en las líneas de ensamble y fabricación metálica de componentes sensibles), para fabricar partes del proceso productivo que incluso pueden ser vendidas a otras corporaciones en una red de alianzas estratégicas para obtener contratos en todas partes del mundo en un contexto de inestabilidad económica.

Antes de continuar a revisar los efectos laborales de esta nueva estrategia de integración productiva, cabe decir que la mayoría de los proveedores son financiados por la propia empresa terminal y por instrumentos de desarrollo públicos como los programas de apoyo a emprendedores que ofrece Nacional Financiera y los distintos fondos de apoyo para la micro, pequeña y mediana empresa (fondos PYME's) que se aplican tanto por el gobierno federal como por gobiernos estatales y a los que se les da mucha difusión. ${ }^{42}$ Un caso especial lo constituyen los apoyos que el Consejo Nacional de Ciencia y Tecnología (Concayt) ha otorgado a Bombardier para impulsar la innovación y el desarrollo tecnológico, los cuales ascendieron en el periodo 2005-2007 a la cantidad de 33.5 millones de pesos. ${ }^{43}$ Esto indica un rasgo de la política industrial actual: el estímulo (mediante la transferencia de recursos públicos a manos privadas) de esta forma de

42 Para mayor detalle de estos instrumentos véase la descripción que hace Nafinsa en su sitio web www.nafin.com [consultado en noviembre de 2014].

43 Bajo el marco del programa de Impulso a la Innovación y Desarrollo Tecnológico a través de estímulos fiscales, mediante el cual se otorgan apoyos a proyectos de investigación de ciertas empresas. En 2005 los apoyos otorgados a Bombardier constituyeron 57.5\% del total de estímulos fiscales otorgados a empresas del estado de Hidalgo; en 2006 y 2007 el porcentaje fue de $87 \%$ y $62 \%$ respectivamente. Datos extraídos de los informes anuales: "La actividad del CONACYT por entidad federativa 2005, 2006 y 2007”, Sistema Integrado de Información sobre Investigación Científica, Desarrollo Tecnológico e Innovación (SIICYT), Base de datos, www.siicyt.gob.mx. A partir de 2008 la información dejó de presentarse de manera desglosada, por lo que no se sabe si ha continuado estas transferencias de recursos públicos hacia Bombardier. www.ohsas.org 
articulación entre el capital trasnacional y el capital nacional, y su conformidad con la transformación de México como un gran taller de proveedores flexibles.

\section{Inestabilidad laboral y vulnerabilidad económica a factores externos}

Con la llegada de Bombardier la producción en México de equipos y material ferroviario se incrementó, crecieron las exportaciones de esta clase y las instalaciones se modernizaron y reconvirtieron tecnológicamente; incluso se ha conformado un clúster ferroviario en la región hidalguense cuyas sinergias alcanzan a varios productores locales. Sin embargo, ahora se resienten más directamente las fluctuaciones económicas externas y con particular intensidad los efectos de las fases recesivas de la economía mundial. Detrás de la solidez tecnológica de la trasnacional se esconde una vulnerabilidad económica que afecta principalmente a la clase trabajadora, pero también a las pequeñas y medianas empresas de la región.

Como ejemplo, entre 2009-2010, debido a una serie de derrotas en varias licitaciones en América Latina para fabricar equipos ferroviarios (incluidas las dos últimas del STC "Metro" de la ciudad de México), Bombardier recortó drásticamente la plantilla de trabajadores eventuales y de base, e incluso anunció la posibilidad de relocalizar sus funciones productivas a otras plantas en Estados Unidos y Canadá, lo que causó temor entre los empresarios y la población de la región, quienes reaccionaron mediante una presión pública en los diarios locales sobre el sindicato de trabajadores de Bombardier Transportation México, para que éste mesurara sus pretensiones laborales:

La firma dedicada a la fabricación de aviones y trenes pasa por una situación difícil, aseguró el mandatario, en la cual el gobierno no puede intervenir por tratarse de un problema entre la sección 200 del Sindicato [...] y la empresa. Mediante el diálogo y negociaciones que se realizan al momento con los trabajadores, la administración estatal espera que se logre un acuerdo para evitar el cierre de la empresa, ya que aseguró no es problemática de falta de capital de Bombardier, ni de procesos de producción, ni de ventas por parte de la firma. 'Es un asunto de convenios con los trabajadores, es lo lamentable, pues no es por la crisis económica, y nos está costando mucho trabajo’, indicó el gobernador [...] Sin embargo, Osorio Chong aceptó que no se han encontrado puntos de coincidencia entre los trabajadores del sindicato y la empresa, por lo que será complejo y difícil que la compañía continúe su operatividad en la entidad $[\ldots]^{44}$

44 Godeleva Pérez, Criterio Hidalgo (23-03-2010), "Bombardier se va de Sahagún, indica Osorio". 


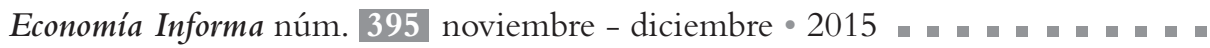

Esta peculiar forma de interpretar el funcionamiento de la compañía (que parece responsabilizar a los trabajadores de las crisis que padece la empresa), se ha traducido en una forma de presión pública y social a través de los medios de comunicación, que ha dado buenos resultados a las compañías asentadas en la zona de Sahagún, pues los escasos sindicatos de trabajadores que aún sobreviven no han podido frenar la precarización laboral.

Tras haber liquidado a un promedio de mil 800 obreros eventuales y de planta, la empresa Bombardier considera la posibilidad de liquidar al total de los trabajadores y su Contrato Colectivo de Trabajo [...] hasta agosto del año pasado, empleaba a 2050 en sus líneas de producción [...] el referido mes inició la liquidación de trabajadores eventuales, quienes fueron saliendo en la medida que se cumplían los programas de producción. Al terminar con los obreros eventuales, se hizo la propuesta de liquidar a la mitad de los 775 empleados de base con la intensión de proteger la fuente de empleo. Se aceptó el recorte de 350 obreros de planta, pero exigieron que fueran los de menor antigüedad [...] la empresa ya planteó la posibilidad de finiquitar a los 233 trabajadores de base que permanecen, así como liquidar el Contrato Colectivo de Trabajo, pero el sindicato no ha respondido. ${ }^{45}$

Este mecanismo funciona de manera tan eficaz que los propios trabajadores se sienten responsables de los males que aquejan a la compañía y aceptan disminuir sus ingresos antes de ver cómo ésta padece. Continuando con la nota anterior, el secretario general del sindicato de trabajadores que labora para Bombardier, "Estableció que a fin de salvar la empresa, están en la disposición de que se realicen paros técnicos o laborar tres días por semana, entre otras opciones". ${ }^{46}$ Cabe aclarar que estas reacciones laborales tienen como trasfondo la amenaza real del cierre de las instalaciones y el peligro de un desempleo prolongado; procesos que tienen fundamentos objetivos derivados de las capacidades de relocalización productiva que posee la compañía canadiense, y que por más que se quieran ignorar son la otra cara de la moneda del proceso de reconversión industrial y del crecimiento de las exportaciones que han dado resonancia internacional a la región hidalguense (para orgullo de los distintos gobiernos locales, identificados con la ideología neoliberal).

Pero los efectos que tiene este particular mecanismo de contención laboral no se limitan sólo a Bombardier. El debilitamiento de los sindicatos de

Artículo consultado en el sitio web www.criteriohidalgo.com (julio de 2015)

45 Sabino Cruz, Juan El Sol de Hidalgo (12-12-2009), "Posible cierre de Bombardier".

46 Ídem. 
industria (como el que trabaja para dicha compañía) tradicionalmente más organizados y combativos, ha sido clave para manejar a otros sindicatos y desmotivar la organización laboral dentro del creciente número de empresa medianas y pequeñas que surgieron como proveedoras de las compañías trasnacionales asentadas en Ciudad Sahagún a raíz del proceso de privatización. Las sinergias productivas que genera Bombardier (la formación del llamado clúster ferroviario), no ha sido la única transformación de largo plazo sobre la fisonomía social de la región; también lo es la precariedad laboral generalizada. Las siguientes conclusiones de un estudio sobre "La responsabilidad social de Bombardier Transportation en Ciudad Sahagún Hidalgo", reflejan el grado de interiorización y aceptación de esta nueva realidad:

Conclusiones: la importancia de Bombardier en Ciudad Sahagún ha sido determinante para la atracción de más empresas a esta zona considerada como industrial, en la época del cierre de las 3 principales empresas DINA, CNCFSA, SIDENA y DIKONA lo que provocó una imagen negativa en esta zona industrial para los inversionistas ya que el sindicalismo de esta región fue un factor de desestabilización social y laboral, que generó una clase laboral muy combativa aunque en beneficio de los trabajadores pero en perjuicio de la industria por sus exageradas peticiones a veces inadecuadas para la economía de las mismas. La forma de manejar esta empresa fue determinante para generar una imagen sobre la importancia de la industria en esta zona que poco a apoco empieza a recuperar su imagen que tuvo años anteriores como una zona importante en el desarrollo nacional de México [se respetó la sintaxis original]. ${ }^{47}$

Pero la situación de precariedad laboral no es exclusiva de México (aunque las respuestas gubernamentales sí llegan a diferir). En 2011 Bombardier U.K., irónicamente último fabricante de trenes de transporte en Gran Bretaña (la cuna del ferrocarril), anunció el despido de 100 trabajadores de su sitio de fabricación en Derby. Los recortes se deben a que el gobierno británico adjudicó un contrato para construir 1200 nuevos coches para la ruta Thameslink a un consorcio liderado por la alemana Siemens, donde la gran mayoría de los trabajos de fabricación se llevarán a cabo en Alemania. La decisión provocó la reacción de United Labour, quien en voz de su secretario general Len McCluskey se expresó así:

47 Piedra Mayorga (02-2014), "Estudio de caso: La responsabilidad social de Bombardier Trasnportation en Ciudad Sahagún Hidalgo”. Escuela Superior de Ciudad Sahagún (filial de la Universidad Autónoma del Estado de Hidalgo). 


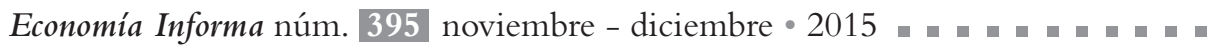

Las graves consecuencias de la decisión equivocada del gobierno de excluir a Bombardier el contrato para construir vagones para el proyecto Thameslink se está convirtiendo en una realidad [...] United trabajará incansablemente para maximizar las bajas voluntarias y bajas naturales y esperamos que la empresa a cooperar plenamente con nosotros, pero, la solución está en el gobierno. Es una tragedia, porque estos despidos habría sido innecesaria si el gobierno realmente se preocupaba de fabricación británica y habilidades británicos. ${ }^{48}$

La nota señala también el grave peligro que corre la cadena de suministro local, que tiene la mayor concentración de empresas de suministro de trenes de la Europa. Irónicamente el entonces canciller británico, George Osborne concluyó su anuncio del presupuesto a principios de 2011 (señala el artículo consultado) con las siguientes exclamaciones (que para Len McCluskey quedaron en palabra muerta): “Queremos que las palabras 'Made in Britain', 'Creado en Gran Bretaña', 'diseñado en Gran Bretaña', 'Inventado en Gran Bretaña’ estén presentes para conducir nuestra nación hacia adelante. A Gran Bretaña llevado en alto por la marcha de los fabricantes. Así es como vamos a crear empleos y apoyar a las familias". ${ }^{9}$

Me pareció pertinente incluir esta cita porque empresas como Bombardier avivan el debate sobre el proteccionismo industrial. Como hace referencia un artículo publicado en octubre de 2010 en España titulado "Las dos caras de Bombardier", ${ }^{50}$ la forma en cómo esta compañía utiliza argumentos a favor del libre mercado para obtener triunfos en licitaciones del gobierno español contrasta fuertemente con su actitud al interior de Canadá, donde recurre frecuentemente al Estado para obtener subsidios a sus exportaciones, estímulos fiscales y beneficios de las políticas científicas y educativas para modernizar constantemente sus instalaciones matrices; así mismo, Bombardier fomenta el uso de políticas proteccionistas en Canadá para desbancar a sus competidores

48 The Guardian (5-07-2011), "Bombardier job cuts: full reaction”, www.theguardian.com 49 Ídem.

50 "Una de cal y otra de arena de Bombardier. La factoría de la empresa canadiense en Trápaga (Vizcaya) destina ya más de la mitad de su producción a la exportación, mientras su campaña nacionalista ha descabalgado a la española CAF de un jugoso contrato con el Metro de Montreal" "[...] de nada ha servido que CAF ofreciese precios más baratos [...] El pasado 5 de octubre el primer ministro de Quebec, jean Charest, anunció que el contrato se adjudicaba al consorcio Bombardier-Alstom. El parlamento quebequés sancionó tres días después una ley ad hoc que no solo adjudica de forma directa el contrato a la oferta francocanadiense sino que cierra las puertas a cualquier reclamación de las otras dos empresas en liza, CAF y la china Zhuzhou [...] las apelaciones españolas a evitar la proteccionista adjudicación a dedo no surtieron efecto. Pesaron más las manifestaciones de trabajadores de Bombardier en Montreal, que tenían supuestamente amenazados 400 empleos". Otero, Lara, El País (24-10-2010), "Las dos caras de Bombardier", www.elpais.com. 
en diversos proyectos de ciudades del país norteamericano, tal como muchos otros autores ya lo han señalado. ${ }^{51}$

Regresando a la cuestión laboral, se pueden encontrar varios ejemplos en otros países de Europa que muestran la relativa facilidad con la que Bombardier relocaliza sus activos a otras partes del mundo en función de sus estrategias de posicionamiento de mercado, reducción de costos, o alianzas estratégicas que ciernen sobre las naciones la posibilidad latente de la desindustrialización y el desempleo. En el caso de México, la posibilidad de relocalización de sus activos y la relativa facilidad con la que se sabe que puede hacerlo y lo ha hecho en otras partes del mundo, se ha convertido en un mecanismo que traslada los costos de la recesiones económicas mundiales y su efecto sobre la caída en los niveles de venta de Bombardier sobre las espaldas de los trabajadores y proveedores locales quienes, para preservar sus ingresos y puestos de trabajo, acatan sin reserva las disposiciones laborales y productivas de la trasnacional. Este mecanismo utiliza la amenaza internacional para provocar la sumisión local.

Una entrevista realizada hace unos años al director de Gunderson-Concarril (socia de Bombardier para algunos proyectos) resume esta pauta de desindustrialización latente:

Un comunicado de prensa emitido por Gunderson Concarril aseguró que el conflicto laboral [en realidad se trató de una revisión salarial y de prestaciones] originó un retraso en las entregas y la falta de fiabilidad percibida por los clientes [...] Por esta razón se va a transferir parte del trabajo que tenía asignado en la planta de Ciudad Sahagún hacia Portland, Oregon, en Norteamérica. Al respecto [...] Guillermo Ramírez, gerente general de Gunderson Concarril, se siente decepcionado porque se había logrado éxito en la obtención de un nivel de trabajo sustancial en las instalaciones de Sahagún para el próximo año; sin embargo, precisa, 'ahora todos esos planes de trabajo se han puesto en riesgo y han dañado la estabilidad de la compañía'. El directivo indica que los compradores de carros de ferrocarril son extremadamente exigentes y esperan las entregas en tiempo y forma, la calidad y fiabilidad son muy importantes para nuestros clientes y para Greenbrier, señaló Guillermo Ramírez. El directivo reconoce que 'mucha de la credibilidad lograda durante este año se comprometió por la desafortunada tensión laboral, difícil de entender'. El gerente general de Gunderson Concarril remata que a pesar de sentirse satisfecho

51 Varios trabajos señalan la enorme cantidad de recursos que han sido transferidos a través de subsidios a Bombardier para apoyar su expansión y posicionamiento a nivel mundial, véase:Vancuver sun (27-08-2013), "Bombardier hasn't had to reimburse taxpayers for all its loans" http://www.vancouversun.com/business. Dunn, Brian, Flight International (28-01-2003), "Bombardier faces asset sale to beat cash crisis" http://www.flightglobal.com. Froese, Marc D. (2010), "Export subsidies: the case of Bombardier regional jets"; pp. 77-95. 


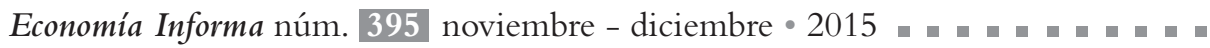

que la huelga fue evitada, espera que tanto el sindicato como Bombardier reflexionen cuidadosamente el daño (económico y social), que ha provocado el conflicto laboral $[\ldots]$ 'ha puesto en tela de juicio la credibilidad laboral de Ciudad Sahagún'. ${ }^{52}$

Como se observa en la cita, al parecer las nuevas pautas productivas en la industria de equipos ferroviarios, a pesar de la reconversión tecnológica, la innovación, la creación de conglomerados y sinergias que abonan la eficiencia de este sector altamente exportador, continúan dependiendo sensiblemente del comportamiento laboral. En este sentido, la propia amenaza de relocalización de activos denuda totalmente la piedra angular del proceso de restructuración de esta industria en los últimos 25 años: la reducción de los costos laborales.

\section{Consideraciones finales}

Se puede decir que la restructuración que vivió la industria de equipos ferroviarios y, en particular, Bombardier-Concarril a partir del proceso de privatización, permitió alcanzar un mayor grado de modernización tecnológica y la inserción plena a las nuevas tendencias productivas mundiales, pero hasta el momento estos recambios en un contexto de crisis mundial han provocado también una mayor vulnerabilidad a los ciclos económicos externos, principalmente para la clase trabajadora y empresarios locales proveedores.

Al respecto hay que recordar que este problema de vulnerabilidad a los ciclos económicos externos orientó buena parte de los esfuerzos de la política económica aplicada en nuestro país durante varias décadas del siglo xx, sobre todo a partir de las décadas de los años treinta y cuarenta en que se buscó superar o por lo menos minimizar los efectos negativos de las crisis externas a medida que se venían presentando de forma más o menos recurrente desde la crisis estadunidense de 1907-08, pero sobre todo después de la gran crisis capitalista mundial de 1929 que mostró las vulnerabilidades de una economía altamente dependiente de la exportación de productos primarios y minerales.

Incluso el proceso de industrialización, cada vez más guiado por el Estado a partir de los años cuarenta, mostró ciertas deficiencias que se exacerbaban a raíz de las fluctuaciones internacionales, como se observó entre 1946-54, después de los desequilibrios externos que causaron las posguerras mundial y de Corea, y que justamente dieron pie a una estrategia más decidida de

52 Torres, Yuvenil, Criterio (2-12-2011), “Conflicto daña productividad en Gunderson” http://criteriohidalgo.com 
promoción del crecimiento económico con base en lo que se creía el sector más dinámico y generador de beneficios para toda la sociedad: la industrialización, mediante diversas estrategias de integración productiva, paulatina mexicanización y promoción de exportaciones (ésta última a partir de 1976).

Todos estos procesos y la forma en cómo se asimilaron por los cuadros promotores y las políticas del periodo, están presente en la creación de Concarril: a) fabricar equipo ferroviario en México para disminuir la renta e importación de equipos usados que limitaba la rehabilitación del sistema ferroviario nacional y contribuía significativamente al déficit de la balanza de pagos; $b$ ) integrar lo más posible la producción en México con base en la asimilación tecnológica y la innovación; c) de esto último se desprende el proceso de reconversión industrial iniciado en 1976. Con todos sus límites, estos esfuerzos no pueden minimizarse por el simple hecho de pertenecer a un pasado paraestatal; hay continuidades que nos alcanzan hasta la fecha. Por tal razón, lo que queda claro con este trabajo es que el proceso de privatización esconde una trama muy compleja, que no puede limitarse sólo a la venta de las empresas paraestatales por sus malos resultados financieros, tal como lo ha querido acotar la ideología neoliberal.

El significado histórico de la privatización de Concarril es, en este sentido, una expresión más de las continuidades y rupturas del siglo xx mexicano, entendido a este como el periodo durante el cual la sociedad mexicana se industrializa y alcanza grados significativos de desarrollo económico, político y social en varias áreas que benefician a importantes grupos de la población. ${ }^{53}$ Ahora, las nuevas pautas productivas en la industria de equipos ferroviarios, encabezada por Bombardier, hace recordar la vulnerabilidad a los ciclos económicos externos que se buscó superar o al menos atenuar en el siglo pasado. La privatización de Concarril en este caso lo que consiguió fue que una industria avanzara en lo productivo, pero a costa de retroceder históricamente a la nación y deteriorar los derechos laborales.

53 Con esta idea se trata de indicar el fin de un ciclo. Se desprende de la metodología teóricohistórica que se propone en el libro de Fujigaki (2013), México en el siglo XX: pasajes históricos. 
Economía Informa núm. 395 noviembre - diciembre • 2015 - "

\section{Bibliografía}

\section{Fuentes de archivo}

Secretaria de Energía, Minas e Industria Paraestatal (1987), CNCF, Informe de labores 1986-1987.

\section{Bibliografía básica}

About us. History [y otros recursos] www.bombardier.com

Boeh, Kevin \& Paul W. Beamish (2007), Mergers and Acquisitions. Text and Cases, Sage Publications Inc., Richard Ivey School of Business, Ontario, Canada.

Bombardier Tnasportation México (2015), Bombardier, la experiencia de invertir en Hidalgo [publicación interna].

Bombardier Transportation México (2013), Bombardier: más de veinte años en México, [publicación interna].

Bombardier Transportation México (2013), Hoja de datos de planta [publicación interna].

Casalet, Mónica, Ed. (2013), La industria aeroespacial. Complejidad productiva e institucional, Concacyt, FLACSO, México.

Escamilla, Adrián (2015), El Complejo Industria Sahagún (1952-1995): conformación, expansión y crisis de una experiencia de industria paraestatal en México; Posgrado de Economía, unAm; México.

Escamilla, Adrián [inédito], "Bombardier y Concarril: historias comparadas. Un análisis histórico económico de los procesos y factores que permitieron el éxito de una y la crisis de la otra".

Froese, Marc D. (2010), "Export subsidies: the case of Bombardier regional jets" en Froese Marc D., Canada at the WTO. Trade litigation and the future of public policy, University of Toronto Press, Canada.

Fujigaki, Esperanza, Coord. (2013), México en el siglo XX: pasajes históricos, unAm, DGAPA-FE; México.

Guajardo, Guillermo (2010), "La industria de equipos ferroviarios en México: de los talleres a la producción trasnacional", H-industria, año 4, núm. 6, primer semestre, Buenos Aires, Argentina.

Ivey Review [varios números], publicación periódica de la Richard Ivey School of Business Foundation, Ontario, Canadá.

Ivey Publishing [varios números], cuadernos de trabajo de la Richard Ivey School of Business Foundation, Ontario, Canadá. 
Izquierdo, Rafael (1995), Política hacendaria del desarrollo estabilizador, 1958-1970; Fondo de Cultura Económica, México.

Lechuga, Marcos [inédito] Memorias.

Macdonald, Larry (2012), The Bombardier story. From snowmobiles to global transportation powerhouse, Wiley, Canada.

Medina Ramírez, Salvador (2013), "El transporte ferroviario en México”, Comercio exterior, vol. 63, núm. 4, México, julio-agosto.

Navarro, Bernardo y Ovidio González (1989), Metro, metrópoli, México; Instituto de Investigaciones Económicas/Unam; UAM-Xochimilco; México.

Piedra Mayorga (02-2014), "Estudio de caso: la responsabilidad social de Bombardier Trasnportation en Ciudad Sahagún Hidalgo". Escuela Superior de Ciudad Sahagún (filial de la Universidad Autónoma del Estado de Hidalgo), México [documento interno].

SHCP (1994), Desincorporación de entidades paraestatales: información básica de los procesos del 1 de diciembre de 1988 al 31 de diciembre de 1993; Fondo de Cultura Económica, México.

SIICYT (varios años), "La actividad del CONACYT por entidad federativa", Sistema Integrado de Información sobre Investigación Científica, Desarrollo Tecnológico e Innovación, México.

\section{Hemerografía}

AFP (14-05-2015), "Cuarta ola de despidos en Bombardier en 18 meses".

CNNEXPANSIÓN (15-01-2015), "Bombardier despedirá a 380 empleados en Querétaro".

CNNEXPANSIÓN (14-05-2015), "Bombardier recortará 1750 puestos de trabajo".

Dunn, Brian, Flight International (28-01-2003), "Bombardier faces asset sale to beat cash crisis"

http://www.flightglobal.com

El economista (2-06-2015), "México liderará producción de arneses de Bombardier". El país (14-11-2001), "Bombardier cerrará tres fábricas y prevé 1050 despidos".

El país (18-02-2004), "Bombardier recorta 6600 empleos y cierra siete plantas en Europa".

El País (2-12-2004), "Nuevos despidos masivos en Deutsche Bank y Bombardier Entrevista a Jacques Rogozinski con Carmen Aristegui (7-07-2011), MVS Noticias. www.noticiasmvs.com 


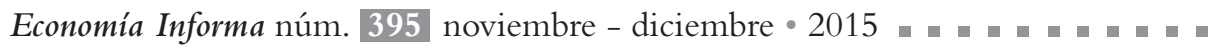

Godeleva Pérez, Criterio Hidalgo (23-03-2010), "Bombardier se va de Sahagún, indica Osorio".

www.criteriohidalgo.com

Otero, Lara, El País (24-10-2010), "Las dos caras de Bombardier", www.elpais.com Sabino Cruz, Juan, El Sol de Hidalgo (12-12-2009), "Posible cierre de Bombardier". The Guardian (5-07-2011), "Bombardier job cuts: full reaction”, www.theguardian. com

Torres, Yuvenil, Criterio (2-12-2011), “Conflicto daña productividad en Gunderson"

http://criteriohidalgo.com

Vancuver sun (27-08-2013), "Bombardier hasn't had to reimburse taxpayers for all its loans"

http://www.vancouversun.com/business.

\section{Sitios web}

http://www.gbrx.com/

[The Greenbrier Companies]

http://www.global-tis.com/

[Global Transporte S. A de C. V.].

www.nafin.com

[Nacional Financiera]

www.isac.tepeapulco.gob.mx

[Directorio de empresas industriales del municipio de Tepeapulco, Hgo.].

https://www.aar.org/

[Association of American Railroads].

www.aws.org/

[American Welding Society].

www.iso.org

[International Organization for Standardization] 
www.ohsas.org

[Occupational Health \& Safety Advisory Services].

www.siicyt.gob.mx

[Sistema Integrado de Información sobre Investigación Científica, Desarrollo Tecnológico e Innovación, CONACYT]. 
Economía Informa núm. 395 noviembre - diciembre • 2015

\begin{tabular}{|c|c|c|c|c|c|c|}
\hline \multicolumn{7}{|c|}{ Equipos fabricados para el Metro de la Ciudad de México 1968-2012 } \\
\hline Modelo & Fabricante & Lugar & Fecha & Lote & $\begin{array}{c}\text { Especificidades/innovacio- } \\
\text { nes/nuevo producto }\end{array}$ & Otros datos relevantes \\
\hline MP-68 & Alsthom & Francia & 1968-1972 & $\begin{array}{l}60 \text { trenes } \\
(9 \text { Unidades } \mathrm{c} / \mathrm{u})\end{array}$ & $\begin{array}{l}\text { Especificidades:Tren eléctrico } \\
\text { de rodadura neumáticaTrac- } \\
\text { ción: JHVentilación: Mono } \\
\text { ventiladores de aluminio }\end{array}$ & $\begin{array}{l}\text { Todas las unidades se } \\
\text { rehabilitaron entre 1993- } \\
2000 \text { en Bombardier- } \\
\text { Concarril. Aún están en } \\
\text { circulación }\end{array}$ \\
\hline NM-73 & $\begin{array}{l}\text { Concarril c/ } \\
\text { Asistencia de } \\
\text { Alsthom }\end{array}$ & México & $1974-1978$ & $\begin{array}{l}43 \text { trenes } \\
(9 \text { Unidades } \mathrm{c} / \mathrm{u})\end{array}$ & $\begin{array}{l}\text { Innovaciones:Ventilación: } \\
\text { Renovación de aire, rejillas de } \\
\text { ventilación y mono ventilado- } \\
\text { res en techo }\end{array}$ & $\begin{array}{l}\text { Todas las unidades se } \\
\text { rehabilitaron entre 1998- } \\
2004 \text { por Alsthom, CAF y } \\
\text { los talleres del sTC.Aún } \\
\text { están en circulación }\end{array}$ \\
\hline NM-79 & $\begin{array}{l}\text { Concarrilc/ } \\
\text { Asistencia de } \\
\text { Alsthom }\end{array}$ & México & 1978-1982 & $\begin{array}{l}58 \text { trenes } \\
(9 \text { Unidades } \mathrm{c} / \mathrm{u})\end{array}$ & $\begin{array}{l}\text { Innovaciones:Tracción: Chop- } \\
\text { perPilotaje automáticoNueva } \\
\text { distribución de asientos }\end{array}$ & $\begin{array}{l}\text { Todas las unidades se } \\
\text { rehabilitaron entre 2004- } \\
2010 \text { por Alsthom, CAF y } \\
\text { los talleres del sTC.Aún } \\
\text { están en circulación }\end{array}$ \\
\hline MP-82 & Alsthom & Francia & 1981-1984 & $\begin{array}{l}23 \text { trenes } \\
(9 \text { Unidades } c / u)\end{array}$ & & $\begin{array}{l}\text { Todas las unidades se } \\
\text { están rehabilitando por } \\
\text { Alsthom a partir de } 2009\end{array}$ \\
\hline $\mathrm{NC}-82$ & Bombardier & Canadá & $1982-1985$ & $\begin{array}{l}20 \text { trenes } \\
(9 \text { Unidades } \mathrm{c} / \mathrm{u})\end{array}$ & & \\
\hline NM-83 & Concarril & México & $1983-1990$ & $\begin{array}{l}55 \text { trenes } \\
(9 \text { Unidades } \mathrm{c} / \mathrm{u})\end{array}$ & & \\
\hline NE-92 & CAF & España & 1992-1994 & $\begin{array}{l}15 \text { trenes } \\
(9 \text { Unidades } \mathrm{c} / \mathrm{u})\end{array}$ & & \\
\hline NM-02 & $\begin{array}{l}\text { Bombardier- } \\
\text { Concarril/ } \\
\text { CAF }\end{array}$ & México & 2002-2006 & $\begin{array}{l}45 \text { trenes } \\
(9 \text { Unidades } \mathrm{c} / \mathrm{u})\end{array}$ & $\begin{array}{l}\text { Innovaciones: Tracción: Mo- } \\
\text { tores asíncronos de corriente } \\
\text { alterna }\end{array}$ & \\
\hline FM-86 & Concarril & México & 1988-1991 & $\begin{array}{l}19 \text { trenes } \\
(6 \text { Unidades } c / u)\end{array}$ & $\begin{array}{l}\text { Nuevo producto:Tren eléctrico } \\
\text { de rodadura férrea con catena- } \\
\text { riaVentilación: Moto ventilado- } \\
\text { res de aluminioFrenos de tipo } \\
\text { semimetálico/aire comprimi- } \\
\text { doPantógrafo de alimentación } \\
\text { de energía }\end{array}$ & \\
\hline FM-95 & $\begin{array}{l}\text { Bombardier/ } \\
\text { CAF }\end{array}$ & México & 1995-1998 & $\begin{array}{l}13 \text { trenes } \\
(6 \text { Unidades } \mathrm{c} / \mathrm{u})\end{array}$ & $\begin{array}{l}\text { Innovaciones:Tableros electró- } \\
\text { nicos }\end{array}$ & \\
\hline FE-07 & CAF & España & $2007-2010$ & $\begin{array}{l}9 \text { trenes } \\
(9 \text { Unidades } \mathrm{c} / \mathrm{u})\end{array}$ & $\begin{array}{l}\text { Innovaciones:En frenos, moto- } \\
\text { res y suspensión }\end{array}$ & \\
\hline FE-10 & CAF & España & 2009-2012 & $\begin{array}{l}30 \text { trenes } \\
(7 \text { Unidades } \mathrm{c} / \mathrm{u})\end{array}$ & $\begin{array}{l}\text { Innovaciones:En frenos, moto- } \\
\text { res y suspensión }\end{array}$ & \\
\hline
\end{tabular}

Fuente: elaboración propia con información obtenida del sitio web: www.metro.df.gob.mx. 